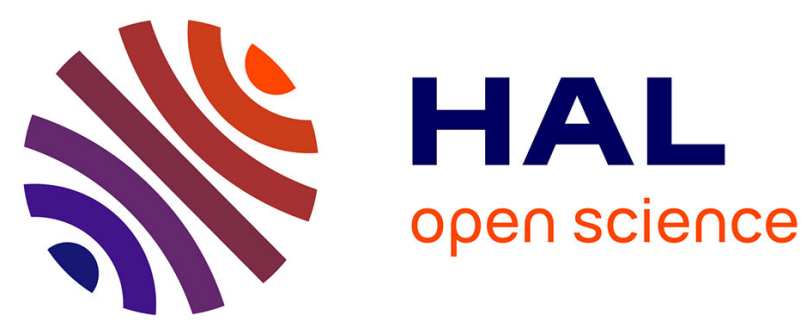

\title{
CHARACTERIZATION OF AlGaAs/GaAs HBTs BY LOCALIZED FILTERED CATHODOLUMINESCENCE
}

C. Dubon-Chevallier, A. Papadopoulo, V. Amarger, C. Besombes, B. Descouts, A. Pougnet

\section{- To cite this version:}

C. Dubon-Chevallier, A. Papadopoulo, V. Amarger, C. Besombes, B. Descouts, et al.. CHARACTERIZATION OF AlGaAs/GaAs HBTs BY LOCALIZED FILTERED CATHODOLUMINESCENCE. Journal de Physique IV Proceedings, 1991, 01 (C6), pp.C6-297-C6-301. 10.1051/jp4:1991645 . jpa00250731

\section{HAL Id: jpa-00250731 https://hal.science/jpa-00250731}

Submitted on 1 Jan 1991

HAL is a multi-disciplinary open access archive for the deposit and dissemination of scientific research documents, whether they are published or not. The documents may come from teaching and research institutions in France or abroad, or from public or private research centers.
L'archive ouverte pluridisciplinaire HAL, est destinée au dépôt et à la diffusion de documents scientifiques de niveau recherche, publiés ou non, émanant des établissements d'enseignement et de recherche français ou étrangers, des laboratoires publics ou privés. 


\title{
CHARACTERIZATION OF AIGaAs/GaAs HBTs BY LOCALIZED FILTERED CATHODOLUMINESCENCE
}

\author{
C. DUBON-CHEVALLIER, A.C. PAPADOPOULO, V. AMARGER, C. BESOMBES, \\ B. DESCOUTS and A.M. POUGNET
}

FRANCE TELECOM, Centre National d'Etudes des Télécommunications, Laboratoire de Bagneux, 196 avenue Henri Ravera, F-92220 Bagneux, France

\begin{abstract}
AlGaAs/GaAs Heterojunction Bipolar Transistors processed with an implanted technology require a Mg implantation to contact the p-type GaAs base layer from the surface and also a low energy $B$ implantation to eliminate the lateral diode between the $\mathrm{n}^{+}$emitter contact layer and the converted p-type region. Low temperature cathodoluminescence spectroscopy has been used to investigate the damage induced by $\mathrm{B}$ implantation. An extensive analysis has then been carried out along chemical bevels to localize the damage induced by the $\mathrm{B}$ implantation inside the structure. Cathodoluminescence has also been used to optimize the annealing process which follows the $\mathrm{Mg}$ implantation in order to recover the defects induced by the implantation.
\end{abstract}

\section{I-Introduction}

AlGaAs/GaAs Heterojunction Bipolar Transistors (HBTs) have shown great potential for their application to high speed circuits, since the intrinsic speed of HBTs is combined with the advantages of bipolar circuits. In this paper, we present the use of low temperature filtered cathodoluminescence (CL) to qualify different processing steps used in the HBTs fabrication technology.

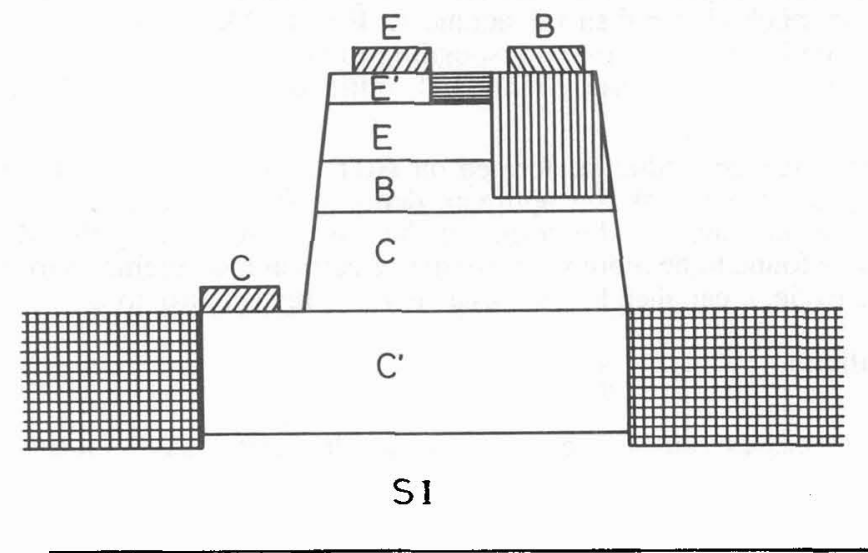

Fig.1: schematic drawing of HBT processed with an implanted technology 
We are developing an implanted technology (figure 1) which permits to achieve easily the processing step of contacting the base layer, while keeping a planar emitter-base junction and also eliminating the current gain size effect related to mesa technology.

In this technology, a Mg p-type implantation is used to contact the base layer. The implantation and annealing processes have been found to be very critical, because of the associated extrinsic resistance and also since the p-type ohmic contact is deposited on the converted layer. The annealing treatment subsequent to the implantation has already been optimized using different electrical characterization techniques [1]. A specific study has been carried out by cathodoluminescence to compare different annealing processes in terms of remaining defects. A low energy B implantation follows the p-type implantation in order to eliminate the lateral diode created by the $\mathrm{Mg}$ implantation between the $\mathrm{n}^{f}$ doped emitter contact $\mathrm{GaAs}$ layer and the $\mathrm{p}^{+}$converted GaAs region. A CL analysis has been carried out in order to investigate the amount of damage induced in the underlying AlGaAs layer.

Low temperature $(10 \mathrm{~K})$ filtered CL spectroscopy is performed in a scanning electron microscope on chemical bevels, under the impact of the electron beam. The CL system has already been described in a previous paper [2]. Because of the low incident beam energy (5 $\mathrm{keV}$ ), the electron-hole pairs are mainly created in a depth of $60 \mathrm{~nm}$ under the surface. The electron beam is focused into a $1 \mu \mathrm{m}$ wide spot and probes the bevel every $50 \mu \mathrm{m}$. Each $50 \mu \mathrm{m}$ step on the bevel corresponds to an explored region $50 \mathrm{~nm}$ deeper in the structure.

\section{II-Mg implantation process}

The annealing cycle has been optimized using different electrical characterization techniques: Hall effect, $\mathrm{C}-\mathrm{V}$ electrochemical profiler, contact resistivity measurements using the Transmission Line Method. The best electrical results were obtained when the annealing cycle was $800^{\circ} \mathrm{C}-10 \mathrm{~s}$. CL analysis has been performed on implanted HBT samples annealed under different conditions: $800^{\circ} \mathrm{C} / 7 \mathrm{~s}(\mathrm{~A}), 850^{\circ} \mathrm{C} / 7 \mathrm{~s}(\mathrm{~B}), 800^{\circ} \mathrm{C} / 10 \mathrm{~s}(\mathrm{C}), 750^{\circ} \mathrm{C} / 7 \mathrm{~s}$ (D). The purpose of this work was to compare the annealing cycles in terms of remaining defects. We have measured the CL intensity from the $\mathrm{p}^{+}$and the $\mathrm{n}^{+}$regions for different positions of the electron beam on the bevel. The cathodoluminescence intensity from the $\mathrm{p}^{+}$region $(\lambda$ around $835 \mathrm{~nm}$ ) is reported in figure 2 for the four samples.

Sample C exhibits a behaviour very different from what obtained for samples A, B and D. Indeed, the CL intensity obtained for samples A, B and D increases and decreases sharply at around $210 \mathrm{~nm}$ on the bevel, which can be explained by the presence in this region of a great density of defects not properly removed by the annealing cycle. There is a second decrease of the emission intensity close to the E-B interface which corresponds to the generation of the carriers in the collector layer. The CL profile is very different for sample C. First of all, the signal intensity is much higher than for sample A, B or D. Moreover, we observe only one maximum of the emission intensity, corresponding to the base layer, which means that there are no remaining defects in the base, emitter and emitter contact layers or at the interfaces.

The cathodoluminescence studies performed on HBT structure allow us to assume that the $800^{\circ} \mathrm{C} / 10 \mathrm{~s}$ cycle, which was the optimum deduced from the electrical characterization studies, is also the optimum for the curing of the defects induced by the $\mathrm{Mg}$ implantation. Moreover, $\mathrm{CL}$ was found to be more sensitive than electrical measurements to small variations of the annealing cycle, it can then be used as a very sensitive control tool.

\section{III-B implantation}

Different processes can be used to eliminate the lateral diode created by the p-type implantation. The use of a low energy boron implantation $\left(50 \mathrm{keV}, 210^{12} \mathrm{at}_{\mathrm{cm}} \mathrm{cm}^{-2}\right)$ allows us to keep a planar emitter-base junction and also to define small structures. As previously described for the $\mathrm{Mg}$ implantation, we have studied on chemical bevels the evolution, at room temperature, of the filtered cathodoluminescence emission before and after the boron implantation. The AlGaAs CL emission intensities before (fig.3(a)) and after (fig.3(b)) implantation are reported as a function of the position of the electron probe on the bevel. 

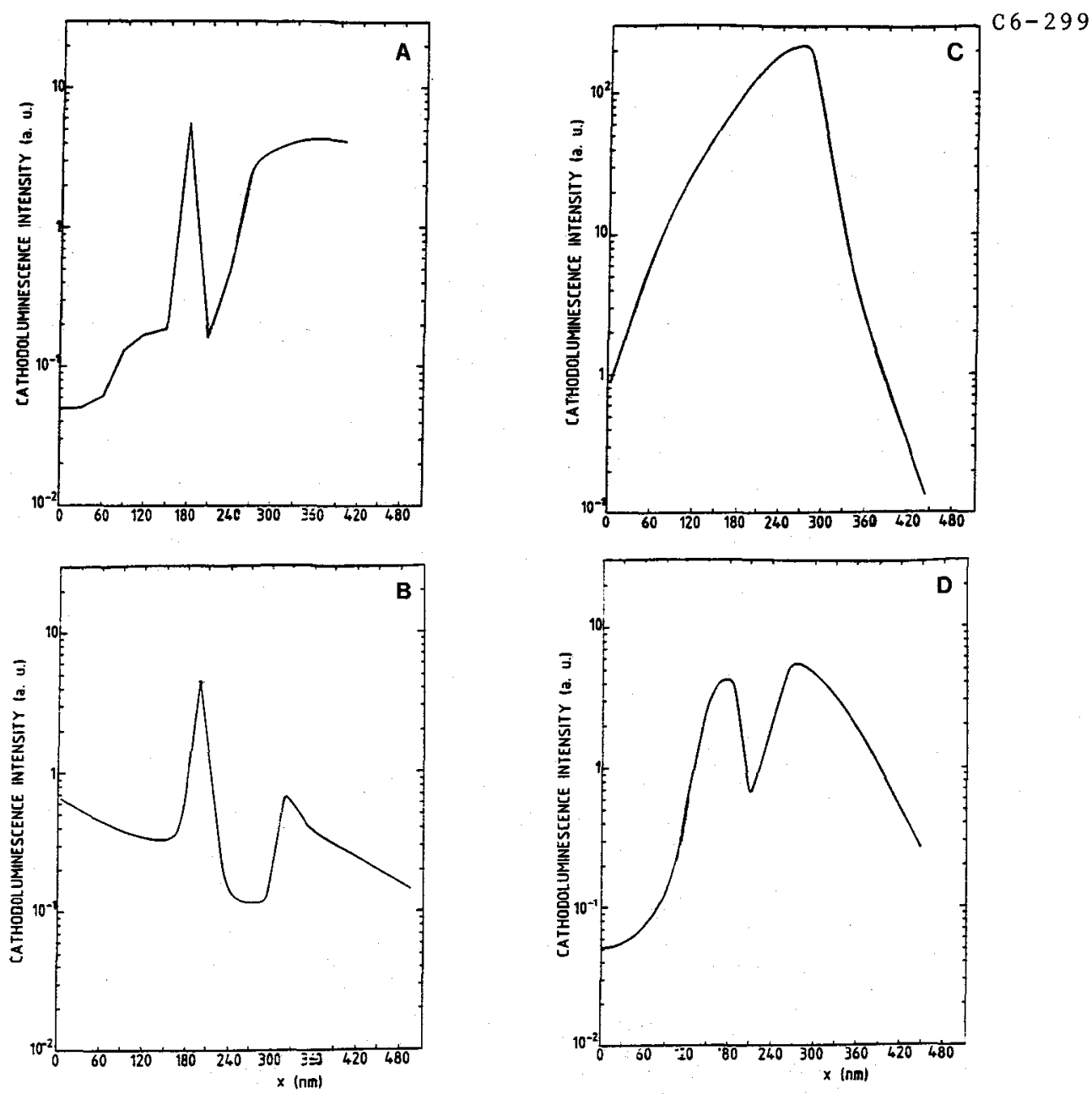

Figure $2(\mathrm{a}, \mathrm{b}, \mathrm{c}, \mathrm{d})$ : CL intensity from the $\mathrm{p}^{+}$region for sample $\mathrm{A}, \mathrm{B}, \mathrm{C}$ and $\mathrm{D}$

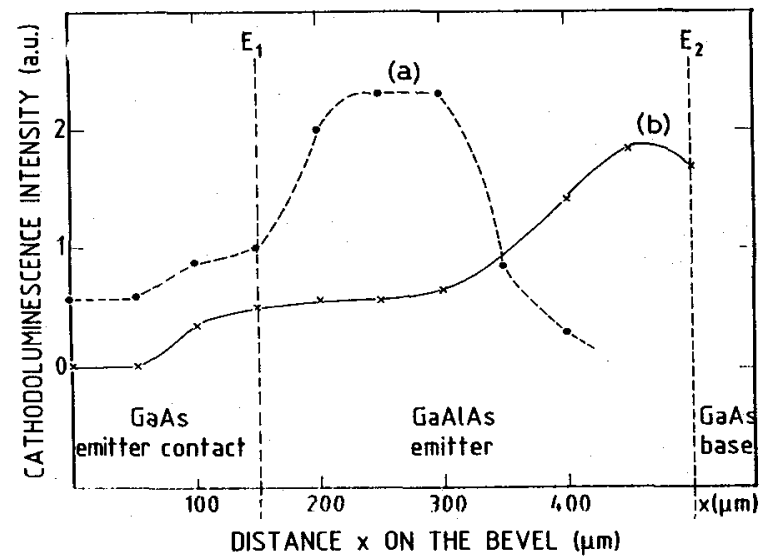

Figure 3: Intensity of the CL emission from the AlGaAs emitter layer before (a) and after (b) implantation 
We can easily detect the influence of the B implantation on the emission from the AlGaAs layer. The displacement of the intensity maximum deeper in the structure is significative of the formation near the $E_{1}$ interface of a damaged region with a high density of non radiative defects. On the contrary, the carriers present near the interface $\mathrm{E}_{2}$ between the emitter and base layers can easily recombine or diffuse towards the GaAs base layer. The maximum of the AlGaAs intensity is then shifted towards the $\mathrm{p}^{+} \mathrm{GaAs}$ base layer and the distance between the position of the maximum before and after implantation is significative of the thickness of the damaged layer which can be evaluated about $200 \mathrm{~nm}$ from the $E_{1}$ interface.

Cathodoluminescence filtered images corresponding to the GaAs emitter contact layer $(\lambda=845$ $\mathrm{nm})$ and to the emitter AlGaAs layer $(\lambda=675 \mathrm{~nm})$, have been obtained at room temperature before and after the implantation process. The images obtained before the boron implantation show a good quality and a good uniformity of the different layers. The images obtained on the implanted sample confirm the electrical desactivation of the emitter contact layer. A great density of non radiative defects (Fig.4) in the AlGaAs layer can also be detected; these defects do not reach the GaAs base layer which is not modified by the implantation process.

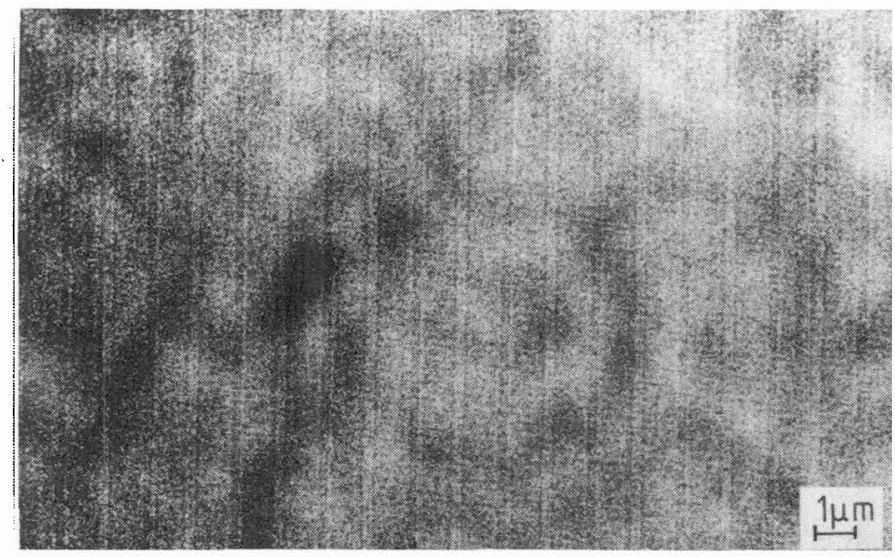

Fig.4: CL image obtained after implantation exhibiting defects with a cellular structure in the AlGaAs layer

The boron implantation is very convenient to eliminate the lateral diode; it allows the total electrical insulation of the emitter contact layer but preserves the base layer, keeping a planar emitter-base junction for the following fabrication steps of the HBT technology.

\section{IV-Conclusion}

Low temperature filtered cathodoluminescence is a very efficient technique to qualify the HBTs fabrication technology. We have presented the use of CL to investigate the amount of damage induced by implantation. CL has been used to qualify the annealing cycle subsequent to the p-type implantation, in order to minimize the amount of remaining defects. It has also been used to investigate the damage induced by a low energy boron implantation, in the layers below the layer which has to be insulated. 


\section{Acknowledgments}

The authors wish to thank Ph.Krauz for technical assistance.

\section{References}

1- V. Amarger, C. Dubon-Chevallier, A.C. Papadopoulo, B. Descouts and Y. Gao, EMRS 27-30 Nov. 1990, to be published in Applied Surface Science.

2- J.F. Bresse, A.C. Papadopoulo, and P. Henoc, Scanning Microscopy Suppl. 1, 205 (1987). 